\title{
An Exact Linearization Method for DC-Side Controllers of Z-Source Inverters in Grid-Tied PV System Applications
}

\author{
Vu Hoang Phuong, Nguyen Manh Linh* \\ Hanoi University of Science and Technology, Hanoi, Vietnam \\ *Email: linh.nguyenmanh@hust.edu.vn
}

\begin{abstract}
This paper presents a new control strategy for grid-connected Z-source inverter which is a part of the residential photovoltaics (PV) system. The control system consists of a DC control loop, which is designed based on the exact linearization method to guarantee that the DC input voltage of the ZSI quickly tracks the reference value which is given by the maximum power point tracking (MPPT) algorithm. By using the proposed control strategy, the maximum power is delivered to the grid despite the variety of environmental temperature and solar irradiation. The effectiveness of the proposed control strategy is verified by simulation using Matlab/Simpower systems under various operating conditions of the PV.
\end{abstract}

Keywords: Z-source inverters (ZSI), grid-tied PV system, an exact linearization method

\section{Introduction}

A practical photovoltaics (PV) system includes multiple arrays connected in parallel and series to achieve sufficient output voltage and power. For an inverter-based PV system that injects power into the grid, the power electronics control is responsible for keeping the DC-link voltage at the input of the inverter at a constant and suitable value so that the injected power to the grid is maximum under different PV operating conditions. This paper presents a control strategy for a grid-tied Z-source inverter (ZSI) for PV system applications. A ZSI has a unified structure with both buck-boost capabilities, and its advantages compared to other inverter configurations are discussed in $[3,5]$

The control scheme at the DC-side of the ZSI is designed based on an exact linearization approach. This proposed method guarantees that the input voltage of the ZSI closely tracks the output reference value provided by the maximum-power-point-tracking (MPPT) algorithm of the PV. Therefore, the power injected into the grid is always at its maximum value under varying conditions of temperature and solar irradiance. The exact linearization effectively handles the nonlinear characteristics in the model of the ZSIbased PV system, which improves the control quality of the entire system compared to the existing works in [4-6].

\section{The Modelling of ZSI and PV}

A PV module consists of multiple PV cells, which are semiconductor components that have $p-n$ junction, which converts solar energy to electrical energy. To achieve a high voltage and power for a grid-tied application, multiple PV modules are connected in series and parallel. In [1], the I-V characteristic of a PV system is given as follows:

$$
\begin{gathered}
i_{p v}=N_{p p} i_{p h}-N_{p p} i_{0}\left[\exp \left(\frac{v_{p v}+\frac{N_{s s}}{N_{p p}} R_{s} i_{p v}}{N_{s s} v_{t} a}\right)-1\right] \\
-\frac{v_{p v}+\frac{N_{s s}}{N_{p p}} R_{s} i_{p v}}{\frac{N_{s s}}{N_{p p}} R_{p}}
\end{gathered}
$$

The model of a PV system is also based on (1).

The model of the ZSI is shown in Fig. 1. It is assumed that the Z-source impedance network is symmetrical, i.e., $i_{L}=i_{L 1}=i_{L 2} ; u_{C}=u_{C 1}=u_{C 2}$. The average models of the Z-source in $d T_{s}$ and (1-d) $T_{s}$ periods are shown in Fig. $1 \mathrm{~b}$ and Fig. 1c. By combining these average models, the average model of the ZSI in one cycle $T_{s}$ is shown in (7).

The average model of the system in Fig. $1 \mathrm{~b}$ is given as follows:

$$
\mathbf{K} \frac{d \mathbf{x}(t)}{d t}=\mathbf{A}_{1} \mathbf{x}(t)+\mathbf{B}_{1} \mathbf{u}(t)
$$$$
\left[\begin{array}{lll}
L & 0 & 0 \\
0 & C & 0 \\
0 & 0 & C_{p v}
\end{array}\right] \frac{d}{d t}\left[\begin{array}{l}
i_{L} \\
u_{C} \\
u_{p v}
\end{array}\right]=\left[\begin{array}{rrr}
0 & 1 & 0 \\
-1 & 0 & 0 \\
0 & 0 & 0
\end{array}\right]\left[\begin{array}{l}
i_{L} \\
u_{C} \\
u_{p v}
\end{array}\right]+\left[\begin{array}{ll}
0 & 0 \\
0 & 0 \\
1 & 0
\end{array}\right]\left[\begin{array}{l}
i_{p v} \\
i_{i n v}
\end{array}\right]
$$ 


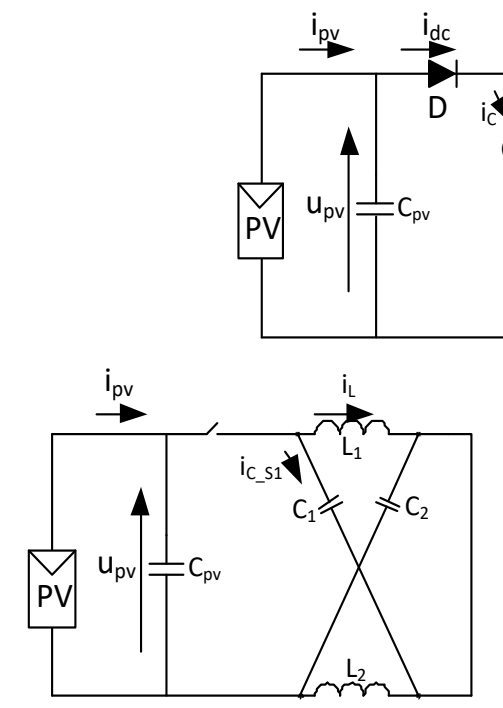

b) a)

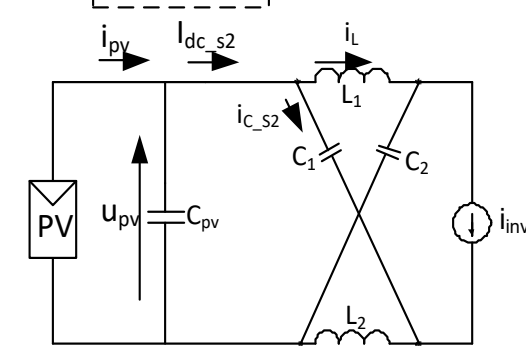

c)

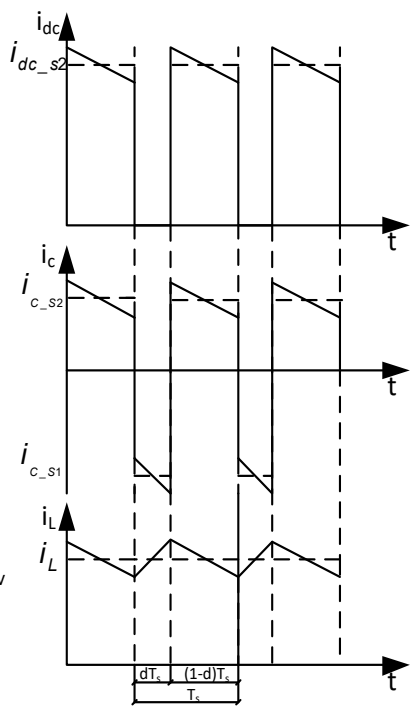

d)

Fig. 1. Model at the dc side of the ZSI

a) Equivalent dc-side circuit of the ZSI connected to PV, b) shoot-through state c) non-shoot-through state, d) currents flowing in ZSI components.

The average model of the system in Fig. 1c is given as follows:

$$
\left\{\begin{array}{l}
L \frac{d i_{L}}{d t}=u_{p v}-u_{C} \\
C \frac{d u_{C}}{d t}=i_{L}-i_{i n v} \\
C_{p v} \frac{d u_{p v}}{d t}=i_{p v}-i_{d c_{-} s 2}
\end{array}\right.
$$

The average current flowing in the capacitors is zero in each cycle. In Fig. 1d, the average value of the current $i_{d c-s 2}$ is shown as follows:

$$
\left\{\begin{array}{l}
i_{d c_{-} s 2}=i_{L}+i_{C_{-} s 2} \\
i_{C}=-d i_{L}+(1-d) i_{C_{-} S 2}=0
\end{array}\right.
$$

or:

$$
\left\{\begin{array}{l}
i_{d c_{-} s 2}=\frac{i_{L}}{1-d} \\
i_{C_{-} S 2}=\frac{d i_{L}}{1-d}
\end{array}\right.
$$

From (3) and (5), the average model of the ZSI is derived as follows:

$$
\begin{gathered}
\mathbf{K} \frac{d \mathbf{x}(t)}{d t}=\mathbf{A}_{2} \mathbf{x}(t)+\mathbf{B}_{2} \mathbf{u}(t) \\
{\left[\begin{array}{lll}
L & 0 & 0 \\
0 & C & 0 \\
0 & 0 & C_{p v}
\end{array}\right] \frac{d}{d t}\left[\begin{array}{l}
i_{L} \\
u_{C} \\
u_{p v}
\end{array}\right]=\left[\begin{array}{rrr}
0 & -1 & 1 \\
0 & 0 & 0 \\
-\frac{1}{1-d} & 0 & 0
\end{array}\right]\left[\begin{array}{l}
i_{L} \\
u_{C} \\
u_{p v}
\end{array}\right]+\left[\begin{array}{rr}
0 & 0 \\
0 & -1 \\
1 & 0
\end{array}\right]\left[\begin{array}{l}
i_{p v} \\
i_{i n v}
\end{array}\right]}
\end{gathered}
$$

By combining (2) and (6), the average model of the model in Fig. 1a is given as follows:

$$
\begin{aligned}
& \mathbf{K} \frac{d \mathbf{x}(t)}{d t}=\left[d \mathbf{A}_{1}+(1-d) \mathbf{A}_{2}\right] \mathbf{x}(t) \\
& +\left[d \mathbf{B}_{1}+(1-d) \mathbf{B}_{2}\right] \mathbf{u}(t)
\end{aligned}
$$

$$
\begin{aligned}
& {\left[\begin{array}{lll}
L & 0 & 0 \\
0 & C & 0 \\
0 & 0 & C_{p v}
\end{array}\right] \frac{d}{d t}\left[\begin{array}{l}
i_{L} \\
u_{C} \\
u_{p v}
\end{array}\right]=} \\
& {\left[\begin{array}{ccc}
0 & (2 d-1) & (1-d) \\
(1-2 d) & 0 & 0 \\
-1 & 0 & 0
\end{array}\right]\left[\begin{array}{l}
i_{L} \\
u_{C} \\
u_{p v}
\end{array}\right]+\left[\begin{array}{cc}
0 & 0 \\
0 & (d-1) \\
1 & 0
\end{array}\right]\left[\begin{array}{l}
i_{p v} \\
i_{i n v}
\end{array}\right]}
\end{aligned}
$$

The model in (7) is the foundation to design the control for the DC side of the ZSI and is a bilinear characteristic. The bilinearity of the (7) is characterized by the multiplication between control signal $d$ and state variable $\mathbf{x}$, hence the system requires a nonlinear control solution. In this paper, we present an approach of using an exact linearization method to design the control for the voltage control loop at the DC side of the ZSI.

\section{Controller Design}

The control structure of a grid-tied ZSI-based PV system is shown in Fig. 2.

The control loops at the $\mathrm{AC}$ side have the setpoints equal to the reference voltage $u_{c_{-} r e f}$ and power factor by regulating the current components $i_{s q}$. On the other hand, the control loop at the DC side has the reference value equal to the output of the MPPT 
algorithm. The control variable is the duty cycle $d$ to achieve the MPP in the I-V characteristic of the PV.

\subsection{AC-Side Controller}

The control loop at the $\mathrm{AC}$ side is responsible for keeping the DC-link capacitor voltage constant as well as regulating the power factor of the PV system. The output of the current loop is the reference signal for the modified space-vector modulation index (MSVM). To reduce the size of the output filters, the MSVM is calculated with the shoot-through state divided into 6 equal sectors for 6 different switching combinations. In addition, to guarantee that the output current is in phase with the grid current, $i_{s q}$ is set to zero. To regulate the power factor of the system, the power factor control loop is designed based on the following equation:

$$
\sin \varphi=\frac{i_{s q}}{\left|i_{s}\right|}=\frac{i_{s q}}{\sqrt{i_{s d}^{2}+i_{s q}^{2}}}
$$

To improve the dynamic performance of the system, this paper uses current loops that are of deadbeat type [7]. The synchronization with the grid voltage is achieved by the phase-lock-loop (PLL) [9].
The structure of the current control loop identifies the reference voltage vector $\mathbf{u}_{\mathrm{s}}$, which is given as follows:

$$
\left\{\begin{array}{l}
u_{s d}(k+1)=\frac{L_{s}}{T}\left[y_{d}(k)+\frac{T}{L_{s}} e_{n d}(k+1)\right] \\
u_{s q}(k+1)=\frac{L_{s}}{T}\left[y_{q}(k)+\frac{T}{L_{s}} e_{n q}(k+1)\right]
\end{array}\right.
$$

where the output y is given as follows:

$$
\left\{\begin{array}{l}
y_{d}(k)=\left[i_{s d}^{*}(k)-i_{s d}(k)\right]-\left(1-\frac{T R_{s}}{L_{s}}\right)\left[i_{s d}^{*}(k-1)-i_{s d}(k-1)\right] \\
-\omega_{s} T\left[i_{s q}^{*}(k)-i_{s q}(k)\right]+y_{d}(k-2) \\
y_{q}(k)=\left[i_{s q}^{*}(k)-i_{s q}(k)\right]-\left(1-\frac{T R_{s}}{L_{s}}\right)\left[i_{s q}^{*}(k-1)-i_{s q}(k-1)\right] \\
+\omega_{s} T\left[i_{s d}^{*}(k)-i_{s d}(k)\right]+y_{q}(k-2)
\end{array}\right.
$$

The outer dc-voltage loop is responsible for regulating the capacitor voltage $u_{C}$ across capacitors $\mathrm{C}_{1}$ and $\mathrm{C}_{2}$ in the impedance network. The dc-voltage controller is designed as a conventional PI controller in the s domain.

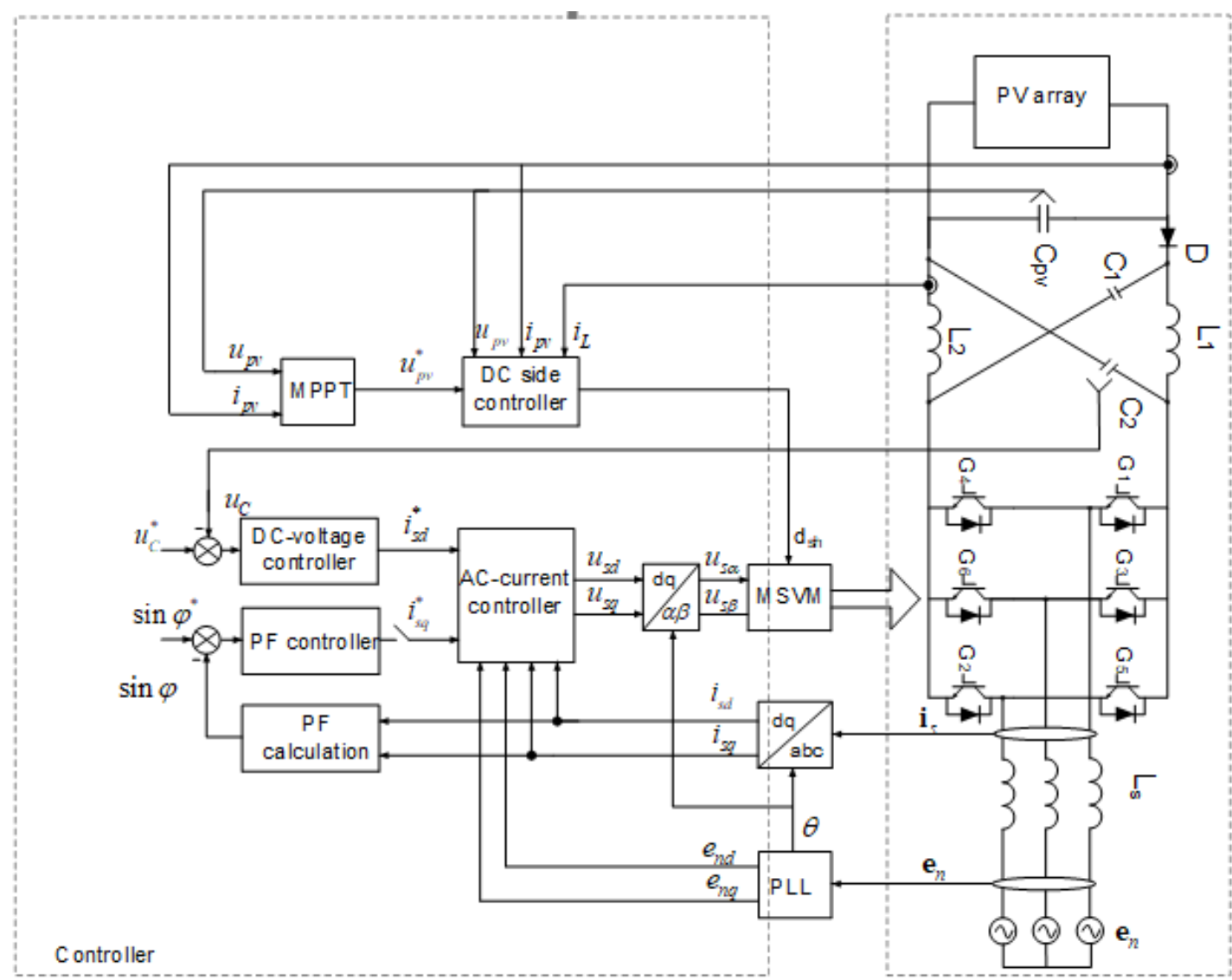

Fig. 2. The control of a Z-source inverter in grid-tied PV system applications 


\subsection{DC-Side Controller}

The voltage control loop at the DC side is responsible for assuring the output voltage of the PV module to follow the reference value identified by the MPPT algorithm. The voltage controller is designed using the exact linearization method discussed in [10]. With this approach, (11) become linear in the state space, as shown below:

$$
\left\{\begin{array}{l}
\frac{d \mathbf{x}}{d t}=\mathbf{f}(\mathbf{x})+\mathbf{h}(\mathbf{x}) u \\
y=g(\mathbf{x})
\end{array}\right.
$$

The voltage $u_{C}$ is kept constant by the voltage control loop shwn in Section 3.1. Equation (7) is rewritten under the form of (11) with functions $\mathbf{f}(\mathbf{x})$, $h(\mathbf{x}), u$, and $\mathbf{g}(\mathbf{x})$ specified in (12). The variable vector $\boldsymbol{x}^{T}=\left[\begin{array}{ll}x_{1} & x_{2}\end{array}\right]^{\mathrm{T}}=\left[\begin{array}{ll}i_{L} & u_{p v}\end{array}\right]^{\mathrm{T}}$

$$
\begin{aligned}
& \mathbf{f}(\mathbf{x})=\left[\begin{array}{l}
\frac{x_{2}-U_{C}}{L} \\
\frac{i_{p v}-x_{1}}{C_{p v}}
\end{array}\right] ; \mathbf{h}(\mathbf{x})=\left[\begin{array}{c}
\frac{2 U_{C}-x_{2}}{L} \\
0
\end{array}\right] ; \\
& g(\mathbf{x})=x_{2} ; \quad u=d
\end{aligned}
$$

The Lie derivation is studied to check relative order of model (11).

$$
\begin{aligned}
& L_{\mathbf{h}} g(\mathbf{x})=\frac{\partial \mathbf{g}}{\partial \mathbf{x}} \mathbf{h}(\mathbf{x})=\left[\begin{array}{ll}
0 & 1
\end{array}\right]\left[\begin{array}{c}
\frac{2 U_{C}-x_{2}}{L} \\
0
\end{array}\right]=0 \\
& L_{\mathbf{f}} g(\mathbf{x})=\frac{\partial \mathbf{g}}{\partial \mathbf{x}} \mathbf{f}(\mathbf{x})=\left[\begin{array}{ll}
0 & 1
\end{array}\right]\left[\begin{array}{c}
\frac{x_{2}-U_{C}}{L} \\
\frac{i_{p}-x_{1}}{C_{p v}}
\end{array}\right]=\frac{i_{p}-x_{1}}{C_{p v}} \\
& L_{\mathbf{h}} L_{\mathrm{f}} g(\mathbf{x})=\frac{\partial L_{\mathbf{f}} g(\mathbf{x})}{\partial \mathbf{x}} \mathbf{h}(\mathbf{x}) \\
& =\left[\begin{array}{ll}
-1 & 0
\end{array}\right]\left[\begin{array}{c}
\frac{2 U_{C}-x_{2}}{L} \\
0
\end{array}\right]=\frac{x_{2}-2 U_{C}}{L} \\
& L_{\mathbf{f}}^{2} g(\mathbf{x})=\frac{\partial L_{\mathbf{f}} g(\mathbf{x})}{\partial \mathbf{x}} \mathbf{f}(\mathbf{x}) \\
& =\left[\begin{array}{ll}
-1 & 0
\end{array}\right]\left[\begin{array}{c}
\frac{x_{2}-U_{C}}{L} \\
\frac{i_{p v}-x_{1}}{C_{p v}}
\end{array}\right]=\frac{U_{C}-x_{2}}{L}
\end{aligned}
$$

Because $x_{2} \neq 2 u_{C}$ so that $L_{\mathbf{h}} L_{\mathbf{f}} g(\mathbf{x}) \neq 0$. The modeling of DC-side of ZSI thus has relative order $r=2$ in the state space. Therefore, it is exactly linearized using feedback state-space control as follows:

$$
u=p(\mathbf{x})+q(\mathbf{x}) w
$$

where

$$
\begin{aligned}
& p(\mathbf{x})=-\frac{L_{\mathbf{f}}^{2} g(\mathbf{x})}{L_{\mathbf{h}} L_{\mathbf{f}} g(\mathbf{x})}=\frac{x_{2}-U_{C}}{x_{2}-2 U_{C}} ; \\
& q(\mathbf{x})=\frac{1}{L_{\mathbf{h}} L_{\mathbf{f}} g(\mathbf{x})}=\frac{L}{x_{2}-2 U_{C}}
\end{aligned}
$$

With the feedback state-space control (4), system (11) becomes linear as follows:

$$
\left\{\begin{array}{l}
\frac{d \mathbf{z}}{d t}=\mathbf{A z}+\mathbf{B} w=\left[\begin{array}{ll}
0 & 1 \\
0 & 0
\end{array}\right] \mathbf{z}+\left[\begin{array}{l}
0 \\
1
\end{array}\right] w \\
y=z_{1}
\end{array}\right.
$$

where the relation between the new state vector $\mathbf{z}$ and old state vector $\mathbf{x}$ is given as follows:

$$
\mathbf{z}=\left[\begin{array}{l}
z_{1} \\
z_{2}
\end{array}\right]=\left[\begin{array}{l}
g(\mathbf{x}) \\
L_{\mathbf{f}} g(\mathbf{x})
\end{array}\right]=\left[\begin{array}{c}
x_{2} \\
\frac{i_{p v}-x_{1}}{C_{p v}}
\end{array}\right]
$$

From (11), the control for the input variable $\omega$ in (16) is given as follows:

$$
\begin{aligned}
& \omega=-2 \xi \omega_{n} \dot{y}-\omega_{n}^{2}(y-\bar{y})= \\
& -k_{2} z_{2}-k_{1}\left(z_{1}-U_{p v_{-} r e f}\right)
\end{aligned}
$$

where $\omega_{n}$ is the natural frequency and $\xi$ is the damping ratio of the second-order system

From (14) and (18), the shoot-through control variable is determined as follows:

$$
\begin{aligned}
& u=\frac{x_{2}-U_{C}}{x_{2}-2 U_{C}}- \\
& \frac{L}{x_{2}-2 U_{C}}\left[k_{1}\left(x_{2}-U_{p v_{-} r e f}\right)+k_{2}\left(\frac{i_{p v}-x_{1}}{C_{p v}}\right)\right]
\end{aligned}
$$

\section{Simulation results}

To demonstrate the effectiveness of the proposed controller, ZSI in a grid-tied PV system is simulated under different operating conditions using Simpower Systems Toolbox in Matlab/Simulink. The simulation parameters of the grid-tied ZSI-based PV system are given in Table 1 . The PV module used in this simulation is SQ160/Shell [12]. 
JST: Smart Systems and Devices

Volume 31, Issue 1, May 2021, 132-139

Table 1. ZSI parameters

\begin{tabular}{|l|c|}
\hline ZSI output voltage & $380 \mathrm{~V} / 50 \mathrm{~Hz}$ \\
\hline $\begin{array}{l}\text { DC-link reference } \\
\text { voltage } U_{C_{-} \text {ref }}\end{array}$ & $570 \mathrm{~V}$ \\
\hline Switching frequency & $5 \mathrm{kHz}$ \\
\hline $\begin{array}{l}\text { Z-source impedance } \\
\text { network }\end{array}$ & $L=1.4 \mathrm{mH} ; C=235 \mu \mathrm{F}$ \\
\hline $\begin{array}{l}\mathrm{C}_{\text {pv }} \\
\text { Grid-side inductor }\end{array}$ & $2 \mathrm{mH}$ \\
\hline $\begin{array}{l}\text { Parameters of the } \\
\text { second order system }\end{array}$ & $\omega_{n}=10 \mathrm{rad} / \mathrm{s}, \xi=0.71$ \\
\hline
\end{tabular}

Table 2. The values of $V_{\mathrm{mp}}$ and $I_{\mathrm{mp}}$ under different operating conditions.

\begin{tabular}{|l|c|c|c|}
\hline \multicolumn{1}{|c|}{ Operating conditions } & $V_{\mathrm{mp}}$ & $I_{\mathrm{mp}}$ & $\begin{array}{c}P_{\mathrm{mp}} \\
(\mathrm{W})\end{array}$ \\
\hline $\begin{array}{l}T=25^{\circ} \mathrm{C}, \\
G=1000 \mathrm{~W} / \mathrm{m}^{2}\end{array}$ & $280 \mathrm{~V}$ & $45.8 \mathrm{~A}$ & 12824 \\
\hline $\begin{array}{l}T=50{ }^{\circ} \mathrm{C}, \\
G=1000 \mathrm{~W} / \mathrm{m}^{2}\end{array}$ & $248 \mathrm{~V}$ & $45 \mathrm{~A}$ & 11160 \\
\hline $\begin{array}{l}T=25^{\circ} \mathrm{C}, \\
G=500 \mathrm{~W} / \mathrm{m}^{2}\end{array}$ & $278 \mathrm{~V}$ & $23 \mathrm{~A}$ & 6394 \\
\hline
\end{tabular}

Assume that the PV system includes 8 identical PV modules in series and 10 identical PV modules in parallel, which have similar operating conditions. The voltage and current at the MPP are identified from the characteristic curve of the Sell - SQ160 PV module specifications under different operating conditions shown in Table 2.

Temperature $T=25{ }^{0} \mathrm{C}$ when $t<0.3 \mathrm{~s}$, $T=50{ }^{0} \mathrm{C}$ when $t>0.3 \mathrm{~s}$ and solar irradiance $G=1000 \mathrm{~W} / \mathrm{m}^{2}$. The simulation results in this case are shown in Fig. 4.

The solar irradiance $G=1000 \mathrm{~W} / \mathrm{m}^{2}$ within $t<0.3 \mathrm{~s}, G=500 \mathrm{~W} / \mathrm{m}^{2}$ within $t>0.3 \mathrm{~s}$ and the temperature $T=25{ }^{\circ} \mathrm{C}$. The simulation results in this case are shown in Fig. 5.

The simulation results in Fig. 4 and Fig. 5 show the input DC voltage of the ZSI always maintains at the value corresponding to the MPP under different operating conditions in Table 2 . The voltage across the capacitors $C_{1}$ and $C_{2}$ are kept at $570 \mathrm{~V}$ and the total harmonic distortion (THD) of the grid-side current $i_{g}$ is $3.09 \%$.

\section{Conclusion}

The paper presents a detailed DC-side model and a control strategy for grid-tied ZSI-based PV systems, which is the foundation to develop other control strategies for the PV system under different operating conditions. The simulation results in Matlab verify the efficacy of the proposed exact linearization method, which guarantees that the ZSI input DC voltage closely tracks the reference value from the MPPT algorithm.

\section{Acknowledgement}

This research is funded by the Hanoi University of Science and Technology (HUST) under project number T2020-SAHEP-004.

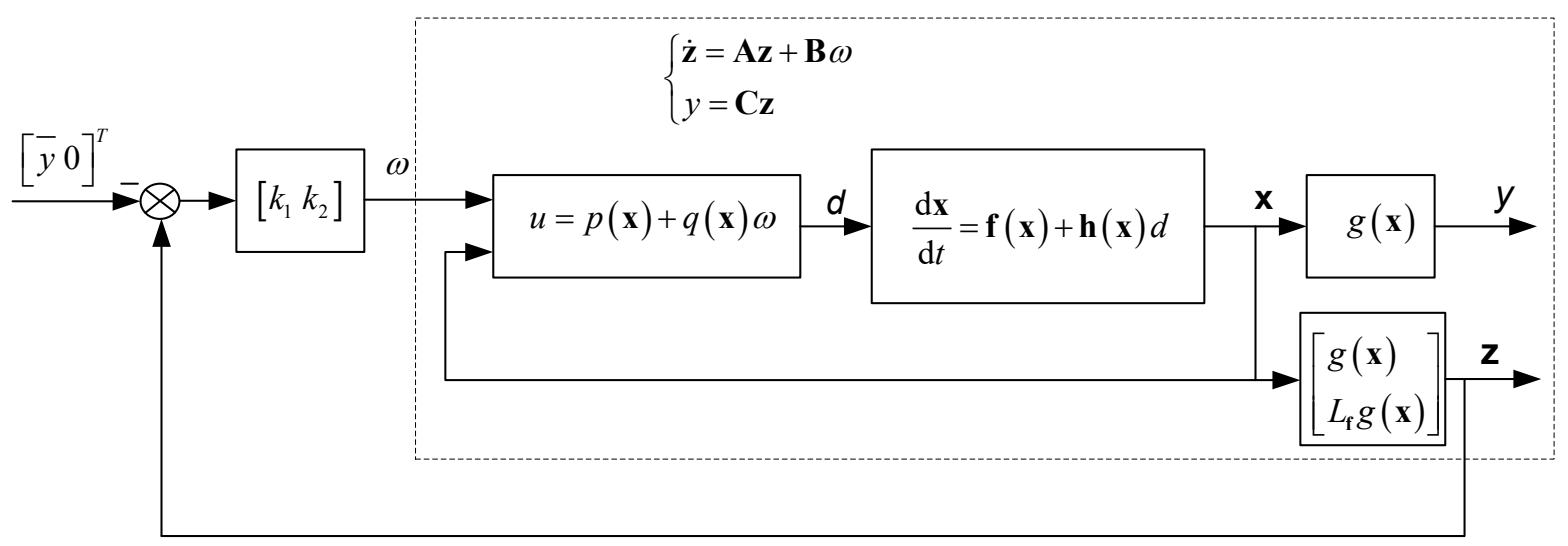

Fig. 3. The DC side controller a Z-source inverter in grid-tied PV system applications 
JST: Smart Systems and Devices

Volume 31, Issue 1, May 2021, 132-139

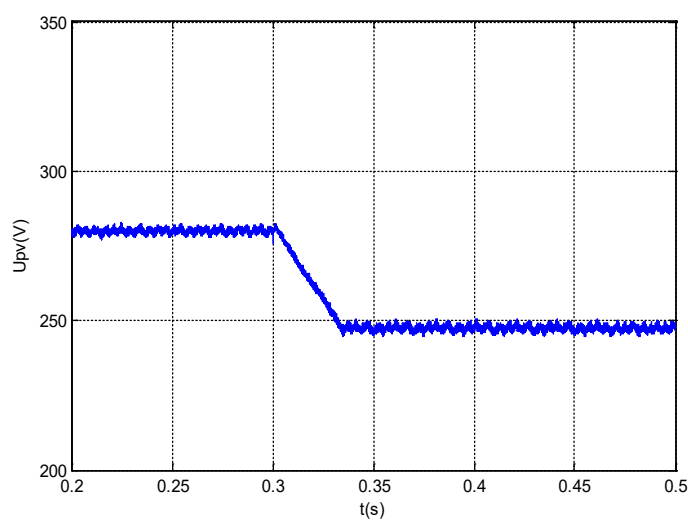

a. Output PV voltage

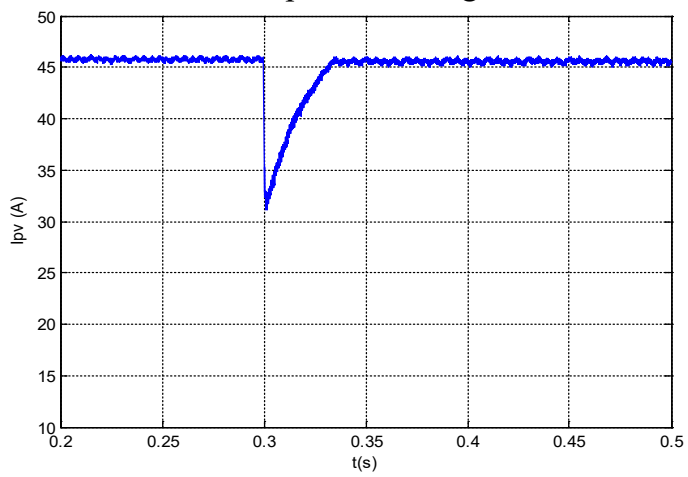

c. Output PV current

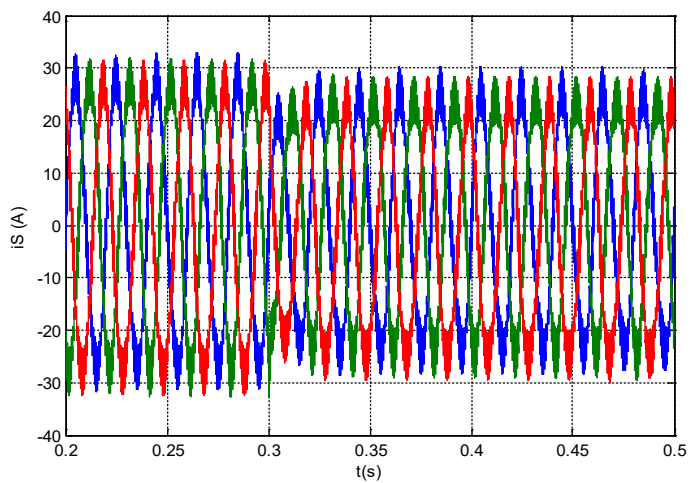

e. Output current of ZSI

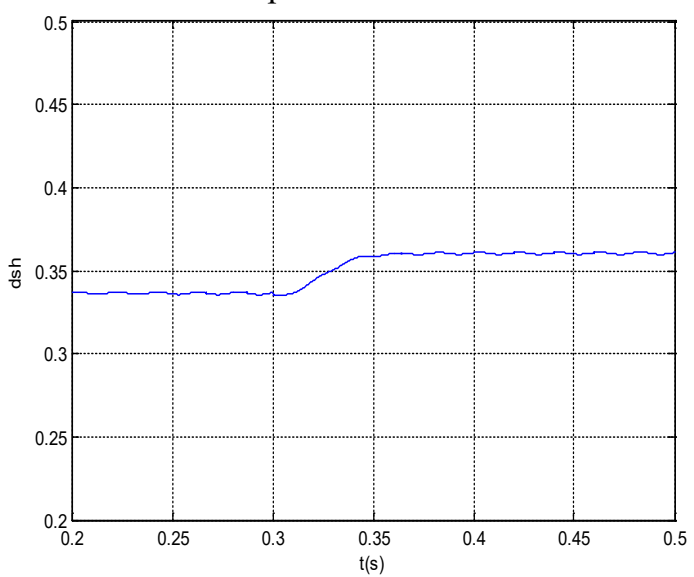

g. Shoot-through duty ratio

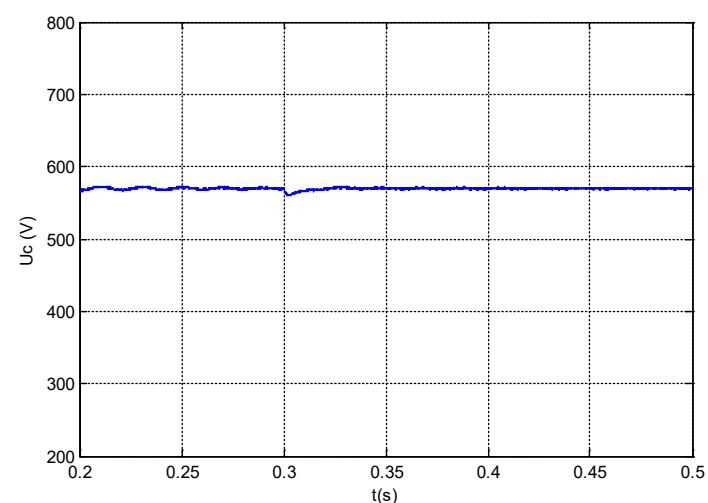

b. Voltage across $\mathrm{C}_{1} \& \mathrm{C}_{2}$

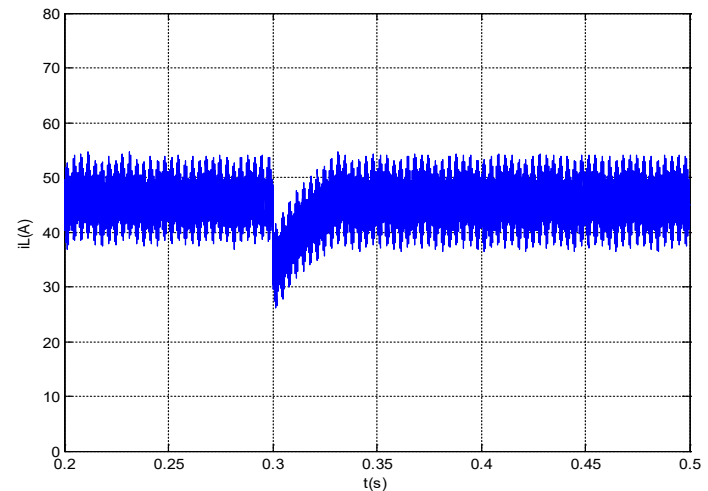

d. Current in $\mathrm{L}_{1} \& \mathrm{~L}_{2}$

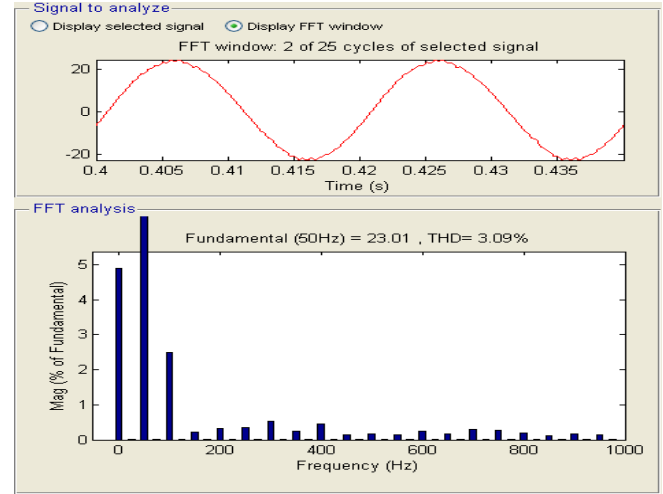

f. Harmonic spectrum of the grid-side current $i_{g}$

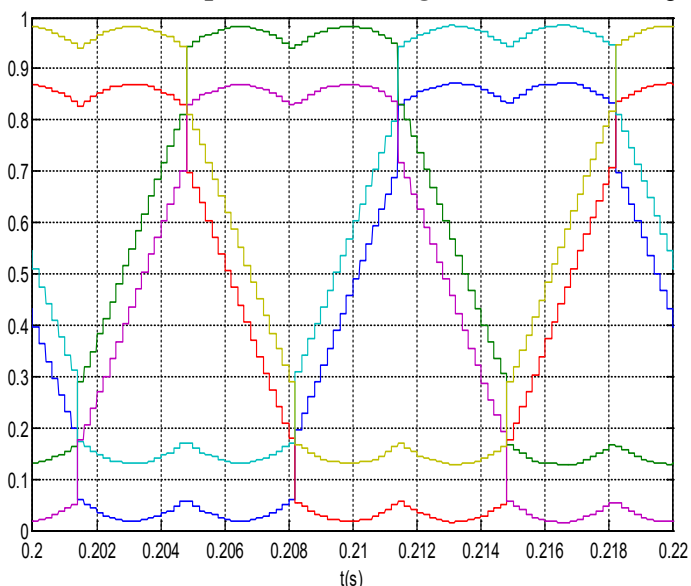

h. Waveforms of space vector modulation

Fig. 4. Simulation results of the system when $T$ changes from 25 to $50^{\circ} \mathrm{C}$ at $t=0.3 \mathrm{~s}, G=1000 \mathrm{~W} / \mathrm{m} 2$ 
JST: Smart Systems and Devices

Volume 31, Issue 1, May 2021, 132-139

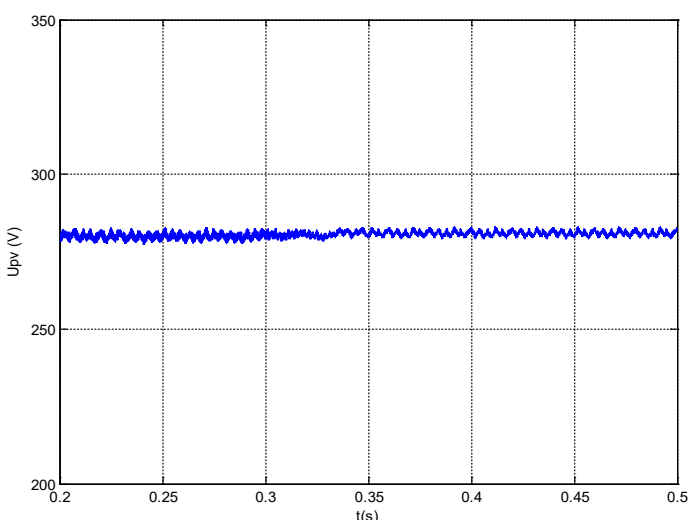

a. Output PV voltage

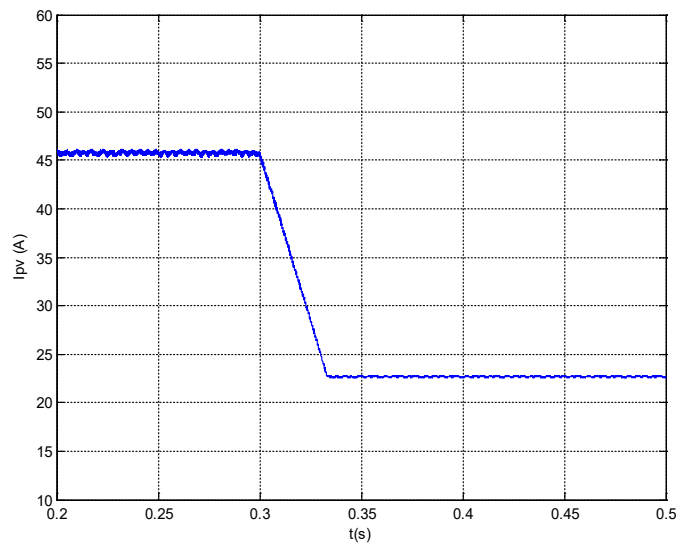

c. Output PV current

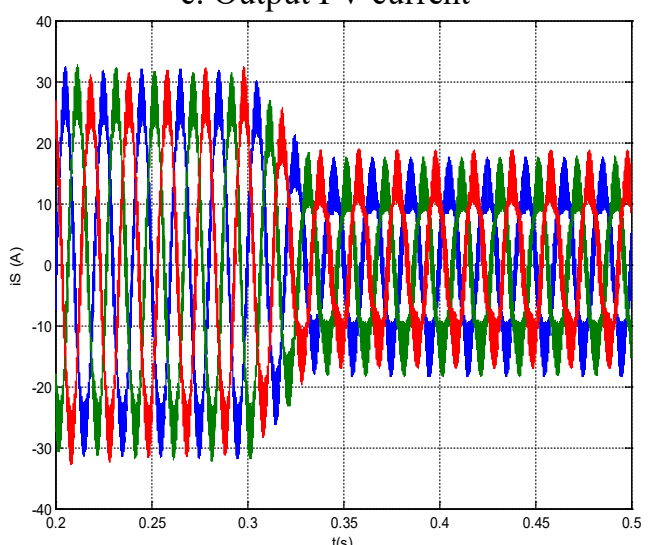

e. Output current of ZSI

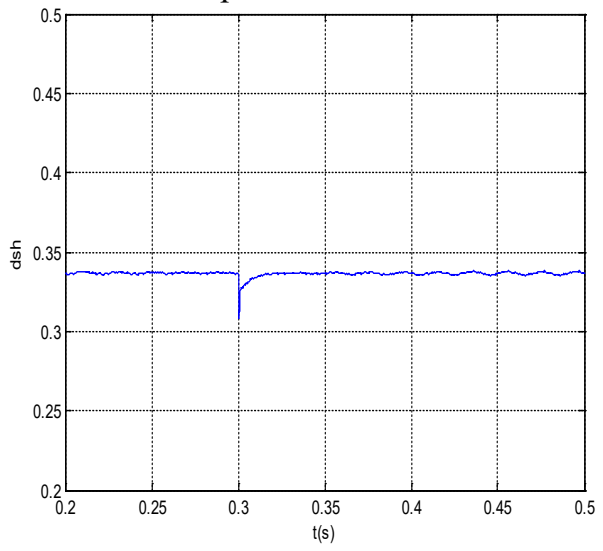

g. Shoot-through duty ratio

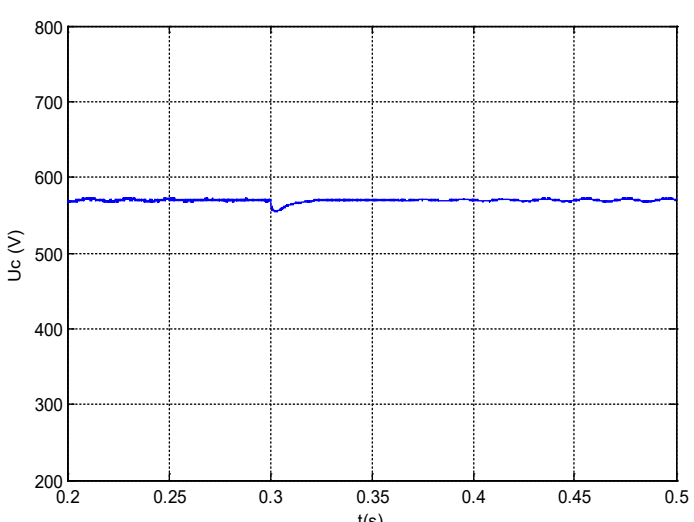

b. Voltage across $\mathrm{C}_{1} \& \mathrm{C}_{2}$

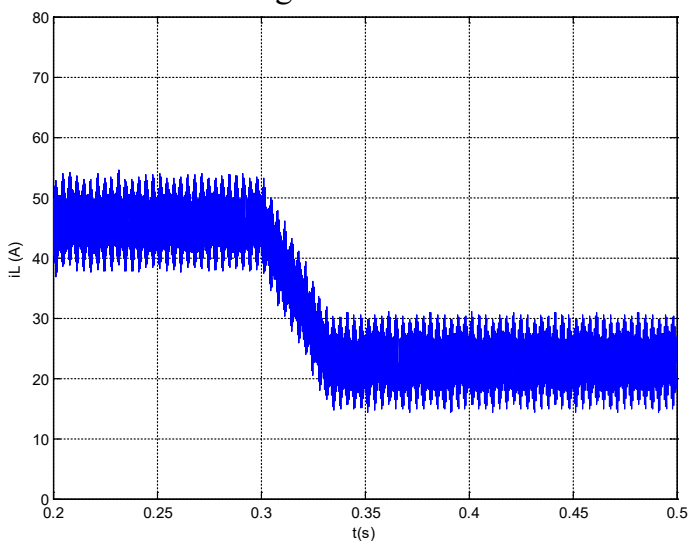

d. Current in $\mathrm{L}_{1} \& \mathrm{~L}_{2}$

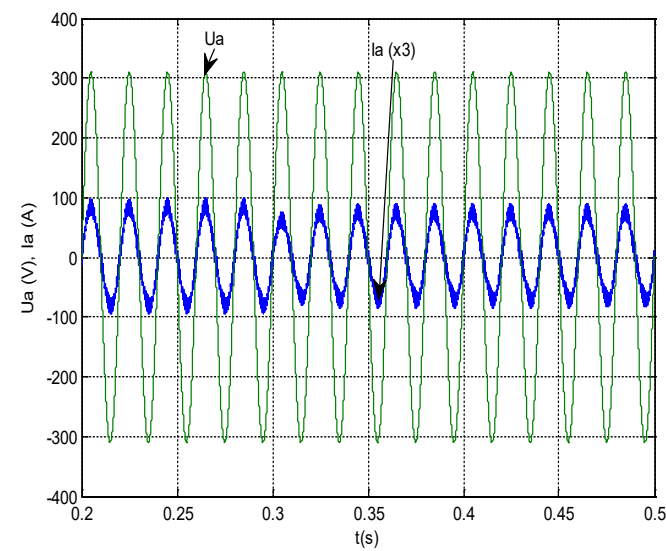

f. Phase A grid voltage and current

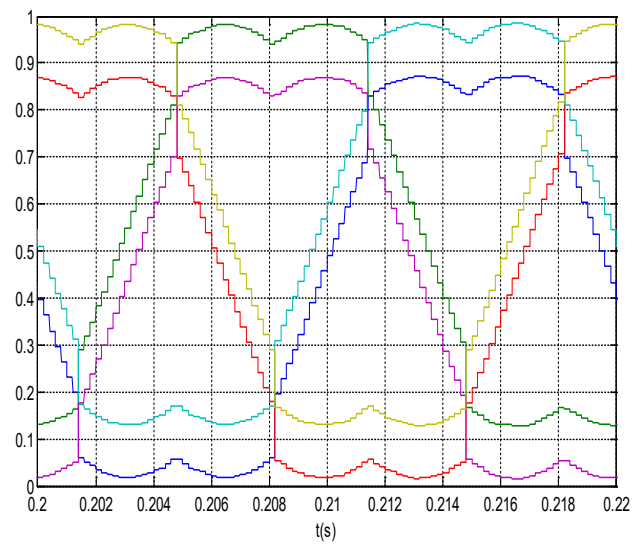

h. Waveforms of space vector modulation

Fig. 5. Simulation results of the system when $G$ changes from $1000 \mathrm{~W} / \mathrm{m} 2$ to $500 \mathrm{~W} / \mathrm{m} 2$ at $t=0.3 \mathrm{~s}, T=25^{\circ} \mathrm{C}$ 


\section{References}

[1] M. G. Villalva, J. R. Gazoli, E. Ruppert F., Modeling and circuit - based simulation of photovoltaic arrays, COBEP'09 Power Electronics Conference, 2009, Brazilian.

https://doi.org/10.1109/COBEP.2009.5347680

[2] Trishan Esram, Patrick L. Chapman, Comparison of Photovoltaic Array Maximum Power Point Tracking Techniques, IEEE Transaction of energy conversion, vol 22, no.2, June 2007.

https://doi.org/10.1109/TEC.2006.874230

[3] Fang Zheng Peng, Z-source inverter, IEEE transactions on industry applications, vol.39, no.2, March/April, 2003.

https://doi.org/10.1109/TIA.2003.808920

[4] Po XU, Xing ZHANG, Chong-wei ZHANG, Renxian, CAO and Liuchen CHANG, Study of Z-Source Inverter for Grid-Connected PV Systems, PESC'06 Power Electronics Specialists Conference, 2006, 37 IEEE.

[5] Xiaogao Chen, QingFu, David Infield, Shijie YU, Modeling and Control of Z-Source Grid-connected PV System with APF Function, Universities Power Engineering Conference (UPEC) 2009, Proceedings of the 44th International.
[6] Antoneta Iuliana Bratcu, Iulian Munteanu, Seddik Bacha, Bertrand Raison, Maximum Power Point Tracking of Grid-connected Photovoltaic Arrays by Using Extremum Seeking Control, Journal of Control Engineering and Applied Informatics (CEAI) Vol.10 No. 4 pp. 3-12 2008.

[7] Phung, Q.N., Jorg-Andreas, D., Vector control of three-phase AC machines, Springer, BerlinHeidelberg, 2008

[8] Tran Trong Minh, Vu Hoang Phuong, Analysis of switching patterns in space vector modulation method for Z source inverter, pp 1-6, No. 91, Journal of Science \& Technology Technical Universities, 2013.

[9] N. Hoffmann, R. Lohde, M. Fischer and F. W. Fuchs, L. Asiminoaei, P.B. Thøgersen, A Review on Fundamental Grid-Voltage Detection Methods under Highly Distorted Conditions in Distributed PowerGeneration Networks, Energy Conversion Congress and Exposition (ECCE), 2011 IEEE. https://doi.org/10.1109/ECCE.2011.6064179

[10] Khalil, Nonlinear Systems, 3rd Edition, Prentice Hall, Upper Saddle River, 2002.

[11] Hebertt Sira-Ramírez and Ramón Silva-Ortigoza, Control Design Techniques in Power Electronics Devices, Springer-Verlag London Limited 2006.

[12] Product Information Sheet, Sell - SQ160, http://www.oksolar.com/pv/shell.htm. 